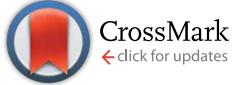

Cite this: RSC Adv., 2017, 7, 12610

Received 6th December 2016 Accepted 7th February 2017

DOI: $10.1039 / c 6 r a 27822 a$

rsc.li/rsc-advances

\section{Comparison of dry and wet milling pre-treatment methods for improving the anaerobic digestion performance of the Pennisetum hybrid}

\author{
Dong Pengyu, ${ }^{\text {ab }}$ Li Lianhua, ${ }^{a}$ Zhen Feng, ${ }^{a}$ Kong Xiaoying, ${ }^{\text {aa }}$ Sun Yongming ${ }^{a}$ \\ and Zhang $\mathrm{Yi}^{\mathrm{ab}}$
}

Two types of milling pre-treatment methods were used to study their effects on the anaerobic digestion performance of the Pennisetum hybrid. The physical structure of the Pennisetum hybrid could be significantly damaged with both milling pre-treatment methods. With an increase in treatment time, the pore volume, surface area, average pore diameter, and the crystallization index of the Pennisetum hybrid increased gradually. The anaerobic fermentation test showed that, among the dry and wet milling pretreatments, the highest specific methane yield was obtained at $3 \mathrm{~h}$ dry milling pre-treated $(358.07 \mathrm{~mL}$ $\mathrm{g}^{-1} \mathrm{VS}$ ) and $6 \mathrm{~h}$ wet milling pre-treated grass $\left(315.87 \mathrm{~mL} \mathrm{~g}^{-1}\right)$, which was $41.04 \%$ and $24.42 \%$ higher than that of the untreated Pennisetum hybrid (253.88 $\mathrm{mL} \mathrm{g}^{-1} \mathrm{VS}$ ). The median diameter (D50) of the Pennisetum hybrid was $25.28 \%$ and $22.36 \%$ lower than that of the untreated Pennisetum hybrid after $3 \mathrm{~h}$ dry and $6 \mathrm{~h}$ wet milling pre-treatment. After wet milling pre-treatment, the fluidity of the Pennisetum hybrid was much better than conventional "smashing" pre-treatment, which may make feeding easier in large-scale biogas projects. Good fluidity and optimization of the degree of milling pre-treatment could, therefore, be applied on an industrial scale in the future.

\section{Introduction}

With the increasing use of energy resources and demand for sustainable development, finding new energy sources has an important role in the development of energy strategies. ${ }^{1}$ Global warming and environmental pollution also require exploration of alternative methods of energy production. ${ }^{2}$ Production of biogas by anaerobic fermentation has huge potential for meeting energy needs. Anaerobic digestion (AD) is a continuous biochemical process. AD can transform many types of biodegradable organic matter to clean, renewable biogas through the metabolism of microorganisms that can biodegrade polymers to $\mathrm{CH}_{4}$ and $\mathrm{CO}_{2} \cdot{ }^{1} \mathrm{AD}$ is usually divided into "thermophilic AD" $\left(55-70{ }^{\circ} \mathrm{C}\right)$ and "mesophilic $\mathrm{AD}$ " $\left(35-37^{\circ} \mathrm{C}\right)$. Compared with thermophilic $\mathrm{AD}$, mesophilic $\mathrm{AD}$ systems exhibit better process stability and higher richness of bacteria. Acidification may occur and then inhibit the production of biogas during thermophilic AD. Other disadvantages of thermophilic AD are: lowquality effluent; increased toxicity and susceptibility to environmental conditions; requirement of larger investment; poor methanogenesis; higher net energy input. In addition, this process is more sensitive to environmental changes than the

${ }^{a}$ Guangzhou Institute of Energy Conversion, CAS Key Laboratory of Renewable Energy, Chinese Academy of Sciences, Guangzhou 510640, China. E-mail: kongxy@ms.giec.ac. cn

${ }^{b}$ University of Chinese Academy of Sciences, Beijing 100049, China mesophilic process. ${ }^{3}$ Although mesophilic systems afford low $\mathrm{CH}_{4}$ yields and suffer from poor biodegradability, the pretreatment of raw materials can, to a certain degree, alleviate these problems.

The sources of raw materials for use as fermentation feedstock are broad: maize straw, wheat straw, and cow dung. Disadvantages in using these raw materials for biogas production include high costs for transportation and storage. Dedicated energy crops make it possible for the bioenergy industry to have an adequate supply of renewable raw materials. ${ }^{4}$ Many perennial energy crops are planted in China's marginal lands: the Pennisetum hybrid, giant reeds, switchgrass, and elephant grass. ${ }^{5}$ The Pennisetum hybrid is promising feedstock for biogas production due to its higher volatile solid (VS) content. ${ }^{6}$ The dry matter content of its leaves accounts for $\approx 50 \%$ of the whole plant. It has strong regeneration ability and can be harvested several times during the growing season. ${ }^{7}$ It has high annual production of 90-120 ton $\mathrm{hm}^{-2}$. $^{8}$ The Pennisetum hybrid can grow on marginal lands because it has high tolerance to hostile environments, and it is anticipated to have a positive impact on the environment. ${ }^{2,5}$

However, bioconversion is inefficient due to the presence of lignocellulosic materials that are difficult to degrade by bacterial hydrolysis. ${ }^{9}$ Lignocellulosic materials mainly consist of three types of polymers-cellulose, hemicellulose, and ligninwhich are associated with each other, as well as smaller amounts of pectin, protein, extractives, and ash. ${ }^{10}$ The lignin is 
closely associated with hemicellulose because it covers cellulose and creates a physical barrier for hydrolytic enzymes. ${ }^{11}$ Furthermore, the cellulose arranges itself in crystalline structures, which are also difficult to degrade. Finally, large particles have a relatively small surface area where the microorganisms can attack the fibers and break down their structures. ${ }^{12} \mathrm{~A}$ reduction of the particle size represents an interesting pretreatment option for solids to be used in biological processes because it is not necessary to add chemical substances and the system is relatively simple. ${ }^{13}$ Smaller particles allow higher kinetics during the biological processes through the release of dissolved organic matter. ${ }^{14}$ Also, smaller particles can stimulate hydrolysis by increasing the surface area and pore volume for the microorganisms to access,${ }^{15}$ and cause a modification of the lignocellulosic structures through alteration of the cellulose crystallinity or lignin distribution. ${ }^{16}$

There are increasing numbers of studies on the pretreatment methods of $\mathrm{AD}$ feedstock. Steam explosion is among the most widely applied thermal pre-treatment methods for enhancing $\mathrm{CH}_{4}$ production from lignocellulosic biomass. However, when a steam explosion is carried out, the release of furans and phenolic compounds may have an inhibitory effect on methanogens, leading to decreased gas production. ${ }^{17}$ "Ensiling" is the most common process used for farm-scale storage of energy crops. Chopped biomass undergoes anaerobic lactic fermentation, but loss of matter is a problem of ensiling pre-treatment. ${ }^{18}$ Enzymatic pre-treatments have been investigated at the laboratory scale. When enzymatic hydrolysis is applied upstream, $\mathrm{AD}$ occurs and there is a strong chance that released sugars are consumed by endogenous microorganisms. Romano et al. ${ }^{19}$ indicated that there was little increase $(\leq 13 \%)$, no impact or even a decrease $(\leq 10 \%)$ in biogas production. The combined effect of thermochemical disperser pre-treatment has been carried out and indicates that biogas production is comparatively higher. Production of volatile fatty acids (VFAs) can reach $675 \mathrm{mg} \mathrm{L}^{-1}$ after thermochemical disperser pretreatment. ${ }^{20}$ Kavitha et al. ${ }^{21}$ investigated the synergistic effects of a combined thermochemical-sonic disintegration technique. However, limited literature is available on milling pre-treatment of the Pennisetum hybrid for biogas engineering.

In the present study, the Pennisetum hybrid was processed in a planetary ball mill at a rotational speed of $600 \mathrm{rpm}$ and a ball : powder ratio of $10: 1$ at room temperature. The planetary ball mill had four ball-grinding jar holders installed on a single planetary disk. When the latter was rotated, the jar axis made planetary movements. With the balls ground and mixed grass at high speed, the grass in the jars was smashed. After pretreatment, the particle size was reduced remarkably. The resulting slurry could be used as raw fermentation material and fed continuously into an anaerobic reactor for biogas production. The purpose of this study was to explore the effect of milling pre-treatments on the structure of the Pennisetum hybrid. Then, the treated Pennisetum hybrid was tested to identify the effect of treatment in mesophilic $\mathrm{AD}$ batch experiments at $35^{\circ} \mathrm{C}$. Then, microbial community analyses were done to assess the changes in microbial communities during $\mathrm{AD}$.
Table 1 Characteristics of the Pennisetum hybrid silage and inoculum for $\mathrm{AD}^{a}$

\begin{tabular}{|c|c|c|}
\hline Analysis & Pennisetum hybrid silage & Inoculum \\
\hline $\mathrm{pH}$ & - & $7.71 \pm 0.04$ \\
\hline TS $(\%)$ & $21.93 \pm 1.02$ & $1.3729 \pm 0.03$ \\
\hline VS (\%) & $19.81 \pm 0.54$ & $0.7566 \pm 0.02$ \\
\hline Total C (\% TS) & $41.85 \pm 0.31$ & $30 \pm 0.42$ \\
\hline Total N (\% TS) & $0.78 \pm 0.00$ & $2.84 \pm 0.11$ \\
\hline $\mathrm{C}: \mathrm{N}$ & $53.65 \pm 0.40$ & $10.56 \pm 0.58$ \\
\hline $\mathrm{NH}_{4}-\mathrm{N}\left(\mathrm{mg} \mathrm{L}^{-1}\right)$ & - & $1168 \pm 8$ \\
\hline Lignin (\% TS) & $19.603 \pm 0.497$ & - \\
\hline Cellulose (\% TS) & $45.01 \pm 1.30$ & - \\
\hline Hemicellulose (\% TS) & $20.05 \pm 0.82$ & - \\
\hline Calorific value $\left(\mathrm{kJ} \mathrm{g}^{-1}\right)$ & $13.20 \pm 0.043$ & - \\
\hline Starch (\% TS) & $15.2 \pm 0.13$ & - \\
\hline Crude fat (\%) & $2.0 \pm 0.05$ & - \\
\hline Crude protein (\%) & $5.2 \pm 0.21$ & - \\
\hline Carbohydrate (\% TS) & $71.3 \pm 2.00$ & - \\
\hline Total sugar (\% TS) & $3.2 \pm 0.12$ & - \\
\hline Water (\% TS) & $10.7 \pm 0.38$ & - \\
\hline
\end{tabular}

\section{Experimental}

\subsection{Substrates and inoculum}

The Pennisetum hybrid (Pennisetum americanum $\times$ P. purpureum) was harvested from the Ruhu district of Guangdong Province (China) on 3 January 2016. The growth stage of the Pennisetum hybrid was set at 2 months so that we could obtain raw material with lower lignin content. No fertilizer was applied during the planting season. The $\mathrm{pH}$, organic matter content, total nitrogen content, total phosphorus content, and total potassium content of the soil was $5.35 \pm 0.1,8.003 \pm 0.4 \mathrm{~g} \mathrm{~kg}^{-1}, 476.66 \pm 4 \mathrm{mg}$ $\mathrm{kg}^{-1}, 313.33 \pm 6 \mathrm{mg} \mathrm{kg}^{-1}$, and $17.46 \pm 0.5 \mathrm{~g} \mathrm{~kg}^{-1}$, respectively. The grass was cut into pieces of length $20 \mathrm{~mm}$ using a hay cutter. Then, the grass was ensiled for 12 weeks in cylindrical plastic buckets (diameter, $0.8 \mathrm{~m}$ ) wrapped in polyethylene foil and subsequently placed in the shade to facilitate bioconversion efficiency. After the silage, the grass was placed in an oven at $80{ }^{\circ} \mathrm{C}$ and removed after $5 \mathrm{~h}$. This is because fresh grass is difficult to crush completely due to bast fiber in the stem; after dehydration the fiber can be crushed more easily. After crushing for $1 \mathrm{~min}$, the substrates were homogenized and subsequently stored at $4{ }^{\circ} \mathrm{C}$ in a refrigerator.

The anaerobic sludge used as the inoculum was collected from an $\mathrm{AD}$ at a cattle farm in Longmen County (Guangdong Province) and then cultured in a mesophilic AD reactor fed with pig manure. Before use, the inoculum was sieved through a 1 $\mathrm{mm}$ mesh to remove large particles and grit. The chemical characteristics of the Pennisetum hybrid and sludge are presented in Table 1.

\subsection{Milling treatment}

A planetary ball mill device was employed to pre-treat the grass hybrid. Milling pre-treatment was done in two ways: (i) "wet" milling (by addition of $1 / 3$ volume of deionized water to the 
milling tank); (ii) "dry" milling (without the addition of water to the milling tank). Four milling times-3, 6, 9, and $12 \mathrm{~h}-$ were used for wet and dry milling (identified as "dry 3", "dry 6", "dry 9", “dry 12", "wet 3", "wet 6", "wet 9", and "wet 12", respectively). A $50 \mathrm{~g}$ (VS) sample was processed for each milling time. A total of $200 \mathrm{~g}$ (VS) samples was processed. The particle-size distribution was analyzed using a laser granulometer. The particle size of the substrate decreased and the surface area increased with milling time.

\subsection{AD}

The $\mathrm{AD}$ equipment consisted of an anaerobic digester (1 L reagent bottle), a biogas collector ( 2 L Erlenmeyer flask), and a water discharge collector (1 L Erlenmeyer flask). The biogas generated in the digester was transported to the head space of the bottle using a glass pipe. Then, the water in the bottle was pressed out and overflowed into the receiver through another glass pipe. The volume of the water discharged from the bottle represented the volume of biogas generated in the digester.

The inoculum and Pennisetum hybrid silage were added at a ratio of $2: 1$ based on VS contents. All reactors were filled with $1000 \mathrm{~mL}$ of the inoculum, and $1.011 \mathrm{~g} \mathrm{~L}^{-1}$ of sodium bicarbonate was added to improve the buffer capacity. The inoculum without addition of any feedstock was used as a control. Reactor headspaces were flushed with $\mathrm{N}_{2}$ and placed in a mesophilic water bath at $35 \pm 1{ }^{\circ} \mathrm{C}$ for 46 days. Each experimental run was carried out in duplicate. The biogas generated was measured every day for the first 7 days and every 3 days for subsequent days. At predetermined days $(0,1,2,3,4,5,6,7,11,15,20,27$, and 39), the content of each reactor was mixed thoroughly and sampled for $\mathrm{pH}$ and VFA, and the microbial community composition was analyzed on days 0,2 , 5, 15, and 35. After termination, the total solids (TS) and volatile solids (VS) contents were analyzed.

\subsection{Analytical methods}

Standard analytical methods were used to determine the TS and VS contents of the inoculum and silage feedstocks. ${ }^{22} \mathrm{C}, \mathrm{N}$, and $\mathrm{H}$ contents were measured using a Vario EL element analyzer. Displacement of saturated brine solutions was used for calculation of daily biogas yield. Mixtures of silage samples $(20 \mathrm{~g})$ and deionized water $(180 \mathrm{~mL})$ were placed in a refrigerator at $4{ }^{\circ} \mathrm{C}$ for $24 \mathrm{~h}$, and then filtered through four-layer gauze. A pH meter (pHS-3C) was used for $\mathrm{pH}$ determination. The concentration of $\mathrm{NH}_{3}-\mathrm{N}$ was determined using a Hach ${ }^{\circledR}$ test kit and spectrophotometer. The VFA contents were determined by a highperformance liquid chromatography system (e2695; Waters, USA) equipped with a refractive index detector, a Shodex sugar $\mathrm{SH}-1011$ column with $0.005 \mathrm{M} \mathrm{H}_{2} \mathrm{SO}_{4}$ as the mobile phase at 0.5 $\mathrm{mL} \min ^{-1}$ and a column temperature of $50{ }^{\circ} \mathrm{C}$. The gas composition $\left(\mathrm{CH}_{4}, \mathrm{CO}_{2}\right.$, and $\left.\mathrm{N}_{2}\right)$ was determined using a gas chromatograph (hp5890) equipped with a thermal conductivity detector and Porpak5 column. The flow rate of the carrier gas (Ar) was $7.5 \mathrm{~mL} \min ^{-1}$, and the temperatures of the injection port, column, and detector, were $30^{\circ} \mathrm{C}, 40^{\circ} \mathrm{C}$, and $120^{\circ} \mathrm{C}$, respectively.
The special surface area, pore size, and total pore volume of the raw materials were analyzed with an automated surface and porosity analyzer (SI-MP-10/Pore Master 33; Quanta Chrome Instruments, USA).

\subsection{Analyses of high-throughput microbial community sequencing data}

2.5.1 DNA extraction, amplification of the 16S rRNA gene, and sequencing. To analyze the structure of the microbial communities in the anaerobic digester, $0.5 \mathrm{~g}$ of sludge at $1,3,7$, 20,30 , and 45 days of incubation was used for DNA extraction. Total DNA was extracted according to a method described. ${ }^{23}$ For sequencing, 16S rRNA genes were amplified with primers $515 \mathrm{~F}$ $\left(5^{\prime}\right.$-GTGYCAGCMGCCGCGGTA-3 $\left.{ }^{\prime}\right)$ and 909R (5'-CCCC GYCAATTCMTTTRAGT- $3^{\prime}$ targeting the bacterial and archaeal V4-V5 region in the $16 \mathrm{~S}$ rRNA gene) with a 10-mer barcode at the $5^{\prime}$ end of primer $515 \mathrm{~F}^{24}$ To minimize polymerase chain reaction (PCR) bias, two PCR reactions were set up for each sample, and the PCR products in the replicate reactions were pooled. The amplicons from each sample were pooled with an equimolar concentration. Then, the PCR products were purified by a DNA gel extraction kit (Sangon Biotech, China). Finally, sequencing to the PCR product was done using an Illumina MiSeq platform (Illumina, USA).

2.5.2 Processing of sequencing data. The raw sequences were sorted based on the unique sample barcodes, trimmed for sequence quality, and denoised using the QIIME pipeline. ${ }^{25}$ Chimera sequences were removed using the UCHIME algorithm. ${ }^{26}$ The sequence number varied among samples, so we randomly resampled the sequences to 5600 reads per sample for further analysis. Then, the sequences were clustered by the complete linkage clustering method in the QIIME pipeline. The sequences were clustered into operational taxonomic units (OTUs) with a threshold of $97 \%$ similarity and assigned to taxonomic classifications using an RDP classifier. Data were expressed as the means \pm standard deviations of the triplicate measurements. Differences between mean values were examined by one-way analysis of variance, and statistical significance was assumed at $P<0.05$.

\section{Results and discussion}

\subsection{Change of physical structure after milling pre-treatment}

The purpose of milling pre-treatment was to increase the surface area and digestibility of the Pennisetum hybrid. Milling could also increase the rates of degradation and volumetric biogas production during the $\mathrm{AD}$ process. Meanwhile, the smaller the particle size, the more likely it is that severe acidification will occur during the fermentation cycle. A decrease in $\mathrm{pH}$ can inhibit the activity of $\mathrm{CH}_{4}$-producing bacteria, which leads to a decrease in $\mathrm{CH}_{4}$ production. Hence, it is necessary to explore the optimal crushing degree of the Pennisetum hybrid to increase the amount of $\mathrm{CH}_{4}$ production while not causing severe acidification.

Table 2 shows the particle-diameter distribution, pore volume, surface area, and average pore diameter of the Pennisetum hybrid before and after pre-treatment. The size of the 
Table 2 Pore volume, surface area, average pore diameter, and particle-diameter distributions of the Pennisetum hybrid silage before and after pre-treatment $^{a}$

\begin{tabular}{|c|c|c|c|c|c|c|}
\hline \multirow[t]{5}{*}{ Dry milling } & Pore volume $\left(\mathrm{cm}^{3} \mathrm{~g}^{-1}\right)$ & $1.52 \times 10^{-3}$ & $4.6 \times 10^{-3}$ & $5.43 \times 10^{-3}$ & $5.57 \times 10^{-3}$ & $7.71 \times 10^{-3}$ \\
\hline & Surface area $\left(\mathrm{m}^{2} \mathrm{~g}^{-1}\right)$ & 1.392 & 2.228 & 2.532 & 2.68 & 3.895 \\
\hline & $\mathrm{D} 10(\mu \mathrm{m})$ & 100.62 & 33.25 & 25.815 & 21.945 & 11.79 \\
\hline & $\mathrm{D} 50(\mu \mathrm{m})$ & 313.8 & 234.46 & 131.75 & 106.12 & 47.92 \\
\hline & $\mathrm{D} 90(\mu \mathrm{m})$ & 1056.45 & 959.8 & 535.52 & 469.22 & 202.25 \\
\hline & Average pore diameter (nm) & 4.37502 & 9.90184 & 12.3670 & 8.95684 & 7.63025 \\
\hline & $\mathrm{D} 10(\mu \mathrm{m})$ & 100.62 & 95.89 & 88.49 & 78.08 & 65.57 \\
\hline & $\mathrm{D} 50(\mu \mathrm{m})$ & 313.8 & 290.87 & 243.64 & 165.96 & 149.94 \\
\hline & $\mathrm{D} 90(\mu \mathrm{m})$ & 1056.45 & 1033.49 & 810.59 & 759.95 & 684.73 \\
\hline
\end{tabular}

${ }^{a}$ Results are shown as means $\pm \operatorname{sd}(n=3)$; $\mathrm{D} X$ indicates that $X \%$ of the sample size is smaller than $\mathrm{D} X$.

surface area reflects the opportunities for contact with anaerobic microorganisms and raw materials, which determines the degree of difficulty for AD. The hydrolysis rate and the degree of cellulose hydrolysis are directly related to the size of the surface area of the raw materials. ${ }^{27}$ For the dry 3 and wet 6 pretreatments, the surface area of the Pennisetum hybrid was $2.228 \mathrm{~m}^{2} \mathrm{~g}^{-1}$ and $2.678 \mathrm{~m}^{2} \mathrm{~g}^{-1}$, respectively, or $60.06 \%$ and $92.39 \%$, higher than that of the untreated grass $\left(1.392 \mathrm{~m}^{2} \mathrm{~g}^{-1}\right)$. The median diameters (D50) of the Pennisetum hybrid were $234.46 \mu \mathrm{m}, 131.75 \mu \mathrm{m}, 106.12 \mu \mathrm{m}$, and $47.92 \mu \mathrm{m}$ for dry 3, 6, 9, and 12 , respectively, or $25.28 \%, 58.01 \%, 66.18 \%$, and $84.73 \%$, lower than that of the untreated Pennisetum hybrid $(313.80 \mu \mathrm{m})$. The median diameters (D50) of the wet 3, 6, 9, and 12 were $290.87 \mu \mathrm{m}, 243.64 \mu \mathrm{m}, 165.96 \mu \mathrm{m}$, and $149.94 \mu \mathrm{m}$, respectively, or $7.3 \%, 22.36 \%, 47.11 \%$, and $52.22 \%$, lower than that of the untreated Pennisetum hybrid. With an increase in treatment time, the pore volume, surface area, and average pore diameter of the Pennisetum hybrid gradually increased. This effect helped to increase the accessibility of the substrate to microorganisms, thus improving the fermentation efficiency.

Milling treatment changed the surface structure of the Pennisetum hybrid and changed its structural characteristics. X-ray diffraction can be used to investigate the change of crystallinity in raw materials. With an increase in treatment time, the cellulose crystallinity index (CrI) of the Pennisetum hybrid increased gradually. This may have been due to the removal of amorphous components, such as hemicellulose and lignin, during the pre-treatment process, which leads to a relative increase in the proportion of crystalline cellulose. The characteristic peak did not shift or diffract, so the milling treatment did not change the cellulose crystal form of the Pennisetum hybrid. ${ }^{28}$ The cellulose in the untreated Pennisetum hybrid was inlaid and wrapped with the hemicellulose and lignin yet, due to the reduction of cellulose and lignin in the treated Pennisetum hybrid, the shape of the characteristic peak became sharp, the width of the half peak was reduced, and the response was enhanced. This shows that the cellulose content of the Pennisetum hybrid increased after the milling treatment, which improved the CrI. A clear relationship between the CrI and the degree of damage to the material structure has been shown in a previous study, ${ }^{29}$ which is in agreement with our experimental results: with an increase in the degree of damage to the material structure, the CrI also increased.

\subsection{Biogas production}

As indicated in Fig. 1a, the specific biogas yields of untreated grass, and the dry 3, 6, 9, and 12 treatments reached 467.33, $676.17,458.51,443.13$, and $395.5 \mathrm{~mL} \mathrm{~g}^{-1}$-VS, respectively. The highest cumulative biogas yield $\left(676.17 \mathrm{~mL} \mathrm{~g}^{-1}\right.$-VS) was obtained with the dry 3 treatment, at $44.68 \%$ higher than that of the un-milled samples. The biogas production decreased for the other pre-treatments compared with that of the untreated Pennisetum hybrid. Also, Fig. 1b shows that the specific biogas yields of untreated grass, and the wet 3, 6, 9, and 12 treatments reached 467.33, 535.17, 577.00, 492.00, and $438.17 \mathrm{~mL} \mathrm{~g}^{-1}$-VS, respectively. The wet 6 treatment had the highest yield, which was $23.47 \%$ higher than that of the untreated grass. This phenomenon could be because the pre-treated Pennisetum hybrid has a larger specific surface area and smaller particle size, which results in the acidification of the reactor. Thus, a reduction in gas production in the corresponding reactor occurs. These results indicated that $>6 \mathrm{~h}$ for dry milled grass and $>9 \mathrm{~h}$ for wet milled grass does not increase the biogas yield. Furthermore, $>6 \mathrm{~h}$ for dry milled grass and $9 \mathrm{~h}$ for wet milled grass inhibited $\mathrm{CH}_{4}$ production.

Biogas $\mathrm{CH}_{4}$ contents are shown in Fig. 1c and d. The $\mathrm{CH}_{4}$ contents of the dry milled grass digesters increased gradually. On day $15, \mathrm{CH}_{4}$ contents reached about $74-77 \%$, and then decreased gradually afterwards. Also, Fig. 1d shows that, in the wet milled grass digesters, the highest $\mathrm{CH}_{4}$ contents $(78.27 \%)$ during the 46 day digestion were obtained with the wet $3 \mathrm{AD}$ on day 27. After day 27, the $\mathrm{CH}_{4}$ contents of all digesters fluctuated between $60 \%$ and $75 \%$.

The specific $\mathrm{CH}_{4}$ yields for the pre-treated Pennisetum hybrid during the 46 days of $\mathrm{AD}$ are presented in Fig. 1e and f. Among the four dry milled grass pre-treatments, the highest specific 

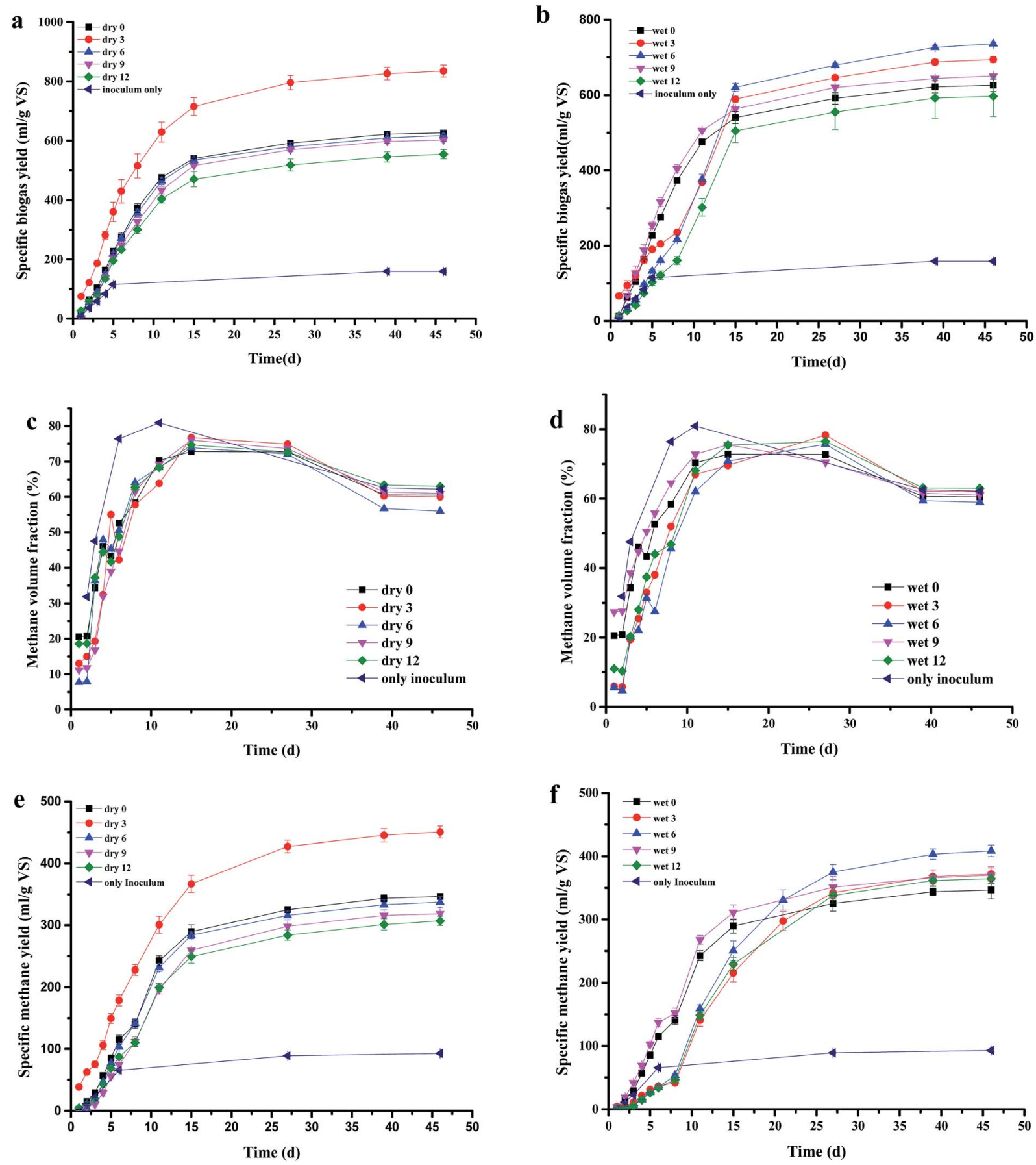

Fig. 1 Biogas production by pre-treated grass: (a) specific biogas yield of dry milled grass, (b) specific biogas yield of wet milled grass, (c) methane volume fraction of biogas from dry milled grass, (d) methane volume fraction of biogas from wet milled grass, (e) specific methane yield of dry milled grass, and (f) specific methane yield of wet milled grass.

$\mathrm{CH}_{4}$ yield was obtained for the dry $3 \mathrm{AD}\left(358.07 \mathrm{~mL} \mathrm{~g}^{-1}\right.$-VS), which was $41.04 \%$ higher than that of the untreated grass $\mathrm{AD}$ $\left(253.88 \mathrm{~mL} \mathrm{~g}^{-1}\right.$-VS), followed by dry $6\left(244.78 \mathrm{~mL} \mathrm{~g}^{-1}\right.$-VS), dry 9 (225.74 $\mathrm{mL} \mathrm{g}^{-1}$-VS), and dry $12\left(214.26 \mathrm{~mL} \mathrm{~g}^{-1}\right.$-VS), respectively. The specific $\mathrm{CH}_{4}$ yields for the wet $3,6,9$, and $12 \mathrm{AD}$ reached $278.99,315.87,277.12$, and $271.55 \mathrm{~mL} \mathrm{~g}^{-1}$-VS, respectively. The wet $6 \mathrm{AD}$ had the largest specific $\mathrm{CH}_{4}$ yield, at $24.42 \%$ higher than that of the untreated grass $\left(253.88 \mathrm{~mL} \mathrm{~g}^{-1}\right.$-VS).
Several analyses have been developed to investigate the effects of pre-treatment on the feedstock of $\mathrm{AD}$ and mainly to describe the improvements in the $\mathrm{CH}_{4}$ yield. "Partial composting" has been investigated as a pre-treatment step in AD. Mshandete et al. ${ }^{30}$ obtained a $26 \%$ higher $\mathrm{CH}_{4}$ yield from sisal pulp pre-treated during $9 \mathrm{~h}$ of composting under aerobic conditions. Alkaline pre-treatment is a suitable method for solubilizing lignin. Sambusiti et al. ${ }^{31}$ investigated the effect of 
alkaline $(\mathrm{NaOH})$ pre-treatment on ensiled sorghum forage in semi-continuous digesters. It was observed that pre-treatment with $10 \mathrm{~g} \mathrm{NaOH} / 100 \mathrm{~g}$ TS increased the $\mathrm{CH}_{4}$ yield by $25 \%$ compared with untreated sorghum. Steam explosion of different lignocellulosic feedstocks has been thoroughly studied and applied at the laboratory scale. Forgacs et al. ${ }^{32}$ studied the co-digestion of steam-exploded citrus waste with municipal solid wastes in continuous reactors and found $\mathrm{CH}_{4}$ production of $0.56 \mathrm{~m}^{3} \mathrm{CH}_{4}$ per $\mathrm{kg}$ VS d. Enzymatic pretreatments have been investigated at the laboratory scale and biochemical methane potential tests showed that the addition of the enzyme to laboratory-scale batch anaerobic tests can lead to an increase in biogas yield of $\approx 10 \% .^{33}$ Several research studies have shown that combined pre-treatment is efficient at enhancing the extent and rate of sludge AD. According to Kavitha et al. ${ }^{34}$ though combined thermochemical-sonic disintegration combination pre-treatment enhanced the preliminary rate of $\mathrm{CH}_{4}$ generation as a result of increased solubilization, it caused only a non-significant increase in $\mathrm{CH}_{4}$ generation. Rani et al. ${ }^{35}$ studied the influence of combined alkaline and disperser pre-treatment on sludge disintegration, and found that biogas production was $76 \%$ higher than that of control at optimized conditions. Our investigation indicated that milling pre-treatment of the Pennisetum hybrid was effective in improving $\mathrm{CH}_{4}$ yield compared with other single pretreatments.

\subsection{Changes in $\mathrm{pH}$ and VFA}

During $\mathrm{AD}$, the $\mathrm{pH}$ value is a significant parameter that is highly sensitive to the buffering capacity and VFA concentration. The $\mathrm{pH}$ values had a completely different trend than VFA concentrations. As shown in Fig. 2e and f, pH values of 6.6-6.7 and 6.46.6 in the dry and wet AD systems were detected at day 4, and at that time the acetic acid reached maximum yields of 2500$3000 \mathrm{mg} \mathrm{L}^{-1}$ and $3500-4000 \mathrm{mg} \mathrm{L}{ }^{-1}$, respectively. The $\mathrm{CH}_{4}$ yields from the dry 6 , dry 9 , dry 12 , wet 9 , and wet $12 \mathrm{AD}$ were relatively lower, which could have been caused by the acidification of the digestion and inhibition of methanogenesis, resulting in falling production of $\mathrm{CH}_{4}$. Thereafter, the $\mathrm{pH}$ values appeared to increase from 7.6 to 7.9 , whereas the VFA concentration decreased, which indicates that VFA was being transformed to $\mathrm{CH}_{4}$.

The evolution of VFAs has a very significant role in guaranteeing the effect of $\mathrm{AD}$, and strongly influences the $\mathrm{pH}$ value, alkalinity, and methanogen activity. ${ }^{16,36}$ Rapid hydrolysis and acidogenesis is a major challenge in $\mathrm{AD}$, and can lead to the accumulation of VFAs. Irreversible acidification and inhibition of methanogenesis would result in failure of the digester. ${ }^{37,38}$ The variations in VFAs during $\mathrm{AD}$ of the milled Pennisetum hybrid are shown in Fig. $2 \mathrm{a}-\mathrm{d}$. The data indicate that the dominant VFA was acetic acid. After starting the test, the concentrations of VFAs for all AD reactors increased rapidly. Among them, as shown in Fig. 2a and c, the concentrations of acetic acid and propionic acid in dry 3 rapidly dropped to about 70-80 $\mathrm{mg} \mathrm{L}^{-1}$ and $200-300 \mathrm{mg} \mathrm{L}^{-1}$, respectively, after a brief increase. The concentrations of acetic acid and propionic acid in dry 6,9 , and 12 reached a maximum of about $2700 \mathrm{mg} \mathrm{L}^{-1}$ and $1400 \mathrm{mg} \mathrm{L}^{-1}$ on day 4 , and then dropped slowly until the digestion process was complete. The decrease in the VFAs concentrations indicates that the production of VFAs is slower than its consumption by methanogenesis. This finding suggests that the hydrolysis of lignocellulose is the rate-limiting step for the AD of the Pennisetum hybrid. Constant $\mathrm{CH}_{4}$ contents of 50$60 \%$ were achieved. Changes in the concentrations of acetic acid and propionic acid are shown in Fig. $2 \mathrm{~b}$ and d, respectively. The highest concentrations of acetic acid and propionic acid were detected in the wet 9 and wet $12 \mathrm{AD}$ reactors, with values of $3500-4000 \mathrm{mg} \mathrm{L}^{-1}$ and $1500-1800 \mathrm{mg} \mathrm{L}^{-1}$, respectively. Conversely, the wet $6 \mathrm{AD}$ system did not show accumulation of acetic acid or propionic acid after 5 days, with values of $80-$ $100 \mathrm{mg} \mathrm{L}^{-1}$ and $400-500 \mathrm{mg} \mathrm{L}^{-1}$, respectively. This phenomenon led to a decline in $\mathrm{CH}_{4}$ production for the dry 6 , dry 9 , dry 12 , wet 9 , and wet $12 \mathrm{AD}$ systems. This could have been because of acid accumulation, at $3000 \mathrm{mg} \mathrm{L}^{-1}$ acetic acid and $1500 \mathrm{mg}$ $\mathrm{L}^{-1}$ propionic acid, and a drop in $\mathrm{pH}$ to 6.5 .

\subsection{Microbial community analyses}

The compositions of the microbial communities were analyzed dynamically to assess how milling pre-treatment impacted the microbial activity and the adaptation of microbial communities to specific processing conditions. As shown in Table 3, the cumulative recovered reading of the dry and wet samples was 1762 583, and the total amount of OTUs was 95 709. OTUs are indicators of the quantity of bacterial communities. The OTUs of the dry milled grass AD were 48516 , slightly higher than that of the wet milled grass (47 193). The Chao1 algorithm was also used to estimate the number of OTUs in microbial communities. The Chao1 and OTUs estimators showed similar trends, and indicated that the bacterial communities for wet milled grass AD had lower richness than those for dry milled grass AD. The diversity of a microbial community can also be reflected by Shannon and Simpson indices. A higher Shannon index indicates a higher diversity of the microbial community, whereas a lower Simpson index indicates higher diversity. The Shannon indices for dry milled grass AD were 4.06-4.66, and for wet milled grass AD they were 3.58-4.57. The Simpson indices were 0.11-0.06 and 0.15-0.04, respectively. The Shannon and Simpson indices showed that dry milled grass $\mathrm{AD}$ had a higher diversity of the microbial community compared with wet milled grass $\mathrm{AD}$. The phenomenon mentioned above explained why the $\mathrm{CH}_{4}$ yield of dry milled grass $\mathrm{AD}$ was better than that for wet milled grass $\mathrm{AD}$. The coverage values of all samples were $>0.95$, indicating that most of the bacteria were within the range of detection.

Principal component analyses indicate changes in the structure of a microbial community during AD. As shown in Fig. 3, principal components 1 (PC1) and 2 (PC2) accounted for $34.14 \%$ and $24.25 \%$ of the total change, respectively. Samples were aggregated into ten groups and identified by Roman numerals. The dry milled treatment samples were divided into groups I, III, IV, IX, and X and a part of group VIII (A-35d, B-35d, D-35d), whereas the other groups contained the wet milled 
a

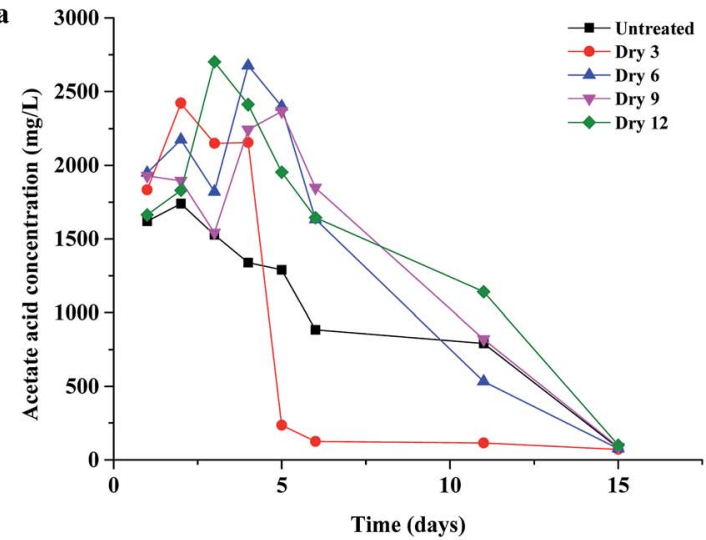

c

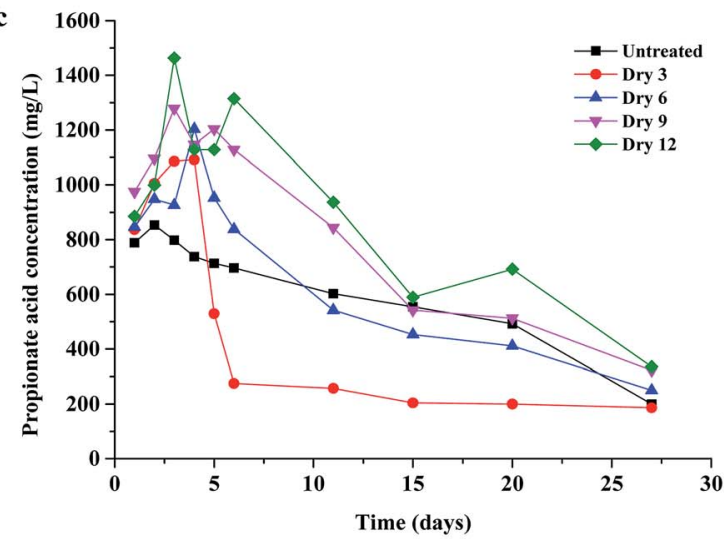

e

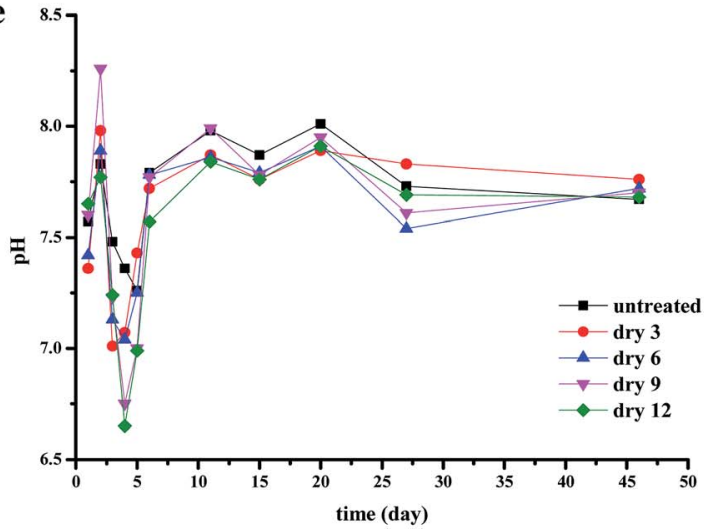

b

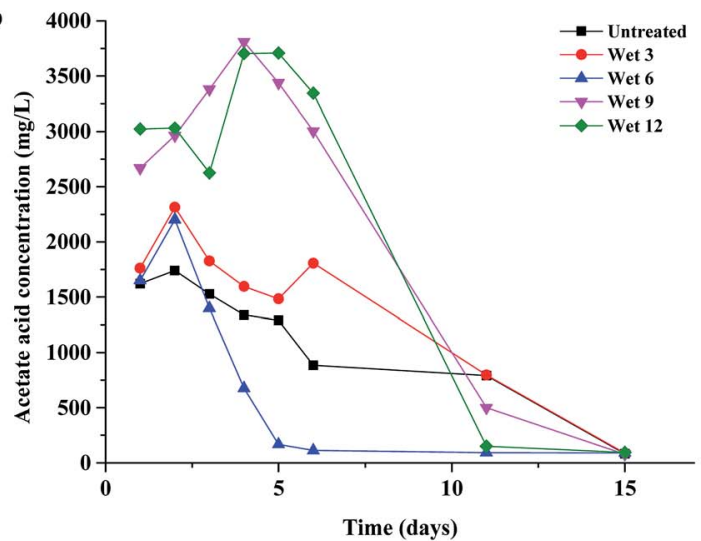

d

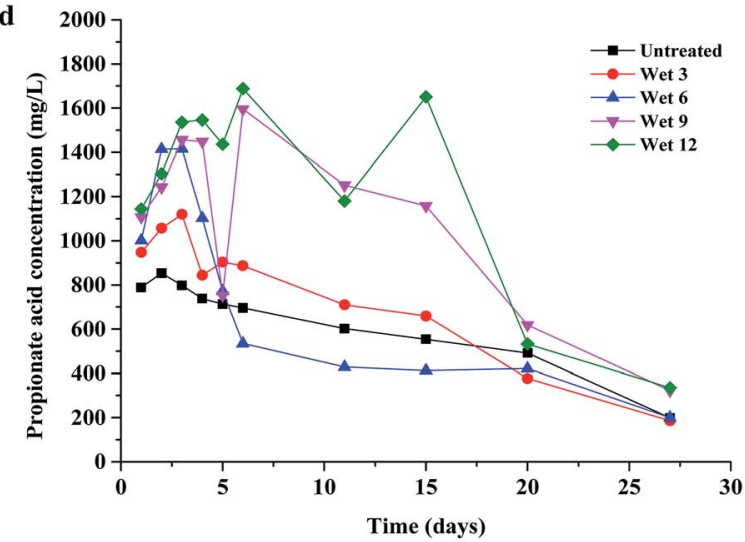

f

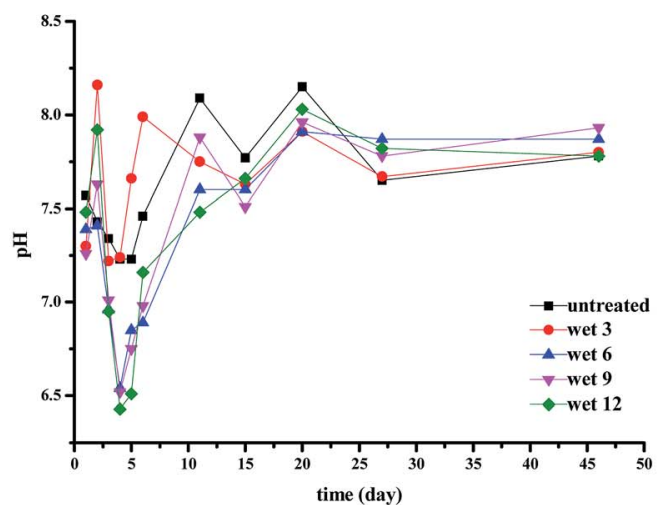

Fig. 2 Production of volatile fatty acids during anaerobic digestion of grass with four levels of pre-treatment: (a) concentrations of acetic acid for dry milled grass, (b) concentrations of acetic acid for wet milled grass, (c) concentrations of propionic acid for dry milled grass, and (d) concentrations of propionic acid for wet milled grass; and change in $\mathrm{pH}$ during anaerobic digestion for (e) dry milled grass and ( $\mathrm{f}$ ) wet milled grass.

treatment samples. Samples for days 1 and 4 of the wet milled grass (c and b) fell into groups II and V, respectively, whereas a and $\mathrm{d}$ fell into group VI, indicating that there was no significant change in the microbial-community structure during the first 4 days of digestion. The microbial-community structure of dry milled grass AD changed little compared with that of wet milled grass $\mathrm{AD}$ during the first 4 days of fermentation, as shown in groups I, III, and IV. This phenomenon indicated that there was no significant difference in the starting speed of all $\mathrm{AD}$ reactors. It is worth noting that sample $\mathrm{A}-4 \mathrm{~d}$ was located in group III, not in group IV like the other day 4 samples. This may have been because dry 3 did not experience serious acidification on day 4. Groups VIII and X indicated that the bacterialcommunity structure of the dry milled grass $\mathrm{AD}$ reached a relatively steady state after 15 days of digestion, whereas the wet milled grass entered stable fermentation much later. This result was consistent with the results for $\mathrm{CH}_{4}$ production and VFAs.

During the AD, various bacterial (Fig. 4a and b) and archaeal (Fig. 4c and d) community structures at the genus level were detected. The dominant genus was the same for all $\mathrm{AD}$ processes, but the relative abundance of each genus was different depending on the pre-treatment type. Dominant bacteria included Levilinea, Bacteroides, Saccharofermentans, Alkalitalea, Acinetobacter, Synergistes, and Proteiniphilum. 
Table 3 Alpha diversity statistics of bacterial communities during digestion

\begin{tabular}{|c|c|c|c|c|c|c|c|}
\hline Fermentation time (days) & Sample & Reads & OTUs & Shannon & Chao1 & Coverage & Simpson \\
\hline \multirow[t]{5}{*}{1} & Dry 3 & 55806 & 3154 & 4.16182 & 16076.96 & 0.956779 & 0.069527 \\
\hline & Dry 6 & 65881 & 3094 & 4.061444 & 16653.25 & 0.964466 & 0.073349 \\
\hline & Dry 12 & 49566 & 2468 & 3.934603 & 11266.44 & 0.963786 & 0.091761 \\
\hline & Wet 3 & 50342 & 2954 & 4.28821 & 15914.84 & 0.955445 & 0.052661 \\
\hline & Wet 6 & 52106 & 2912 & 4.217762 & 14153.36 & 0.958488 & 0.050612 \\
\hline \multirow[t]{6}{*}{4} & Dry 3 & 44738 & 2593 & 4.552737 & 11772.70 & 0.958022 & 0.037974 \\
\hline & Dry 6 & 57400 & 2846 & 4.091292 & 14290.80 & 0.962997 & 0.064667 \\
\hline & Dry 9 & 65840 & 3317 & 4.176026 & 15842.01 & 0.961984 & 0.060175 \\
\hline & Dry 12 & 59216 & 3004 & 4.144411 & 15862.06 & 0.961885 & 0.056986 \\
\hline & Wet 3 & 53723 & 2715 & 4.204539 & 14759.27 & 0.961339 & 0.04807 \\
\hline & Wet 6 & 49341 & 2691 & 4.350349 & 14441.16 & 0.958655 & 0.043056 \\
\hline & Dry 9 & 56790 & 3351 & 4.288492 & 19883.22 & 0.954147 & 0.063166 \\
\hline & Dry 12 & 59693 & 3052 & 4.031164 & 14938.78 & 0.961419 & 0.075797 \\
\hline & Wet 3 & 27819 & 1742 & 4.598299 & 8076.64 & 0.956217 & 0.032259 \\
\hline & Wet 6 & 47790 & 2798 & 4.565135 & 13479.78 & 0.956413 & 0.040131 \\
\hline & Wet 9 & 52524 & 2972 & 4.347882 & 15072.07 & 0.958 & 0.051466 \\
\hline & Wet 12 & 54758 & 3035 & 4.234921 & 13465.01 & 0.959129 & 0.080019 \\
\hline \multirow[t]{6}{*}{35} & Dry 3 & 46840 & 2675 & 4.204925 & 13471.70 & 0.957899 & 0.084436 \\
\hline & Dry 6 & 53967 & 3280 & 4.299125 & 13595.23 & 0.956177 & 0.082486 \\
\hline & Dry 9 & 61836 & 3321 & 4.379049 & 14150.71 & 0.961689 & 0.065638 \\
\hline & Dry 12 & 58822 & 2910 & 4.060932 & 11422.52 & 0.9652 & 0.111108 \\
\hline & Wet 3 & 75160 & 3605 & 4.660527 & 19655 & 0.964396 & 0.033939 \\
\hline & Wet 6 & 53420 & 3342 & 4.663317 & 15567.63 & 0.954549 & 0.055168 \\
\hline
\end{tabular}

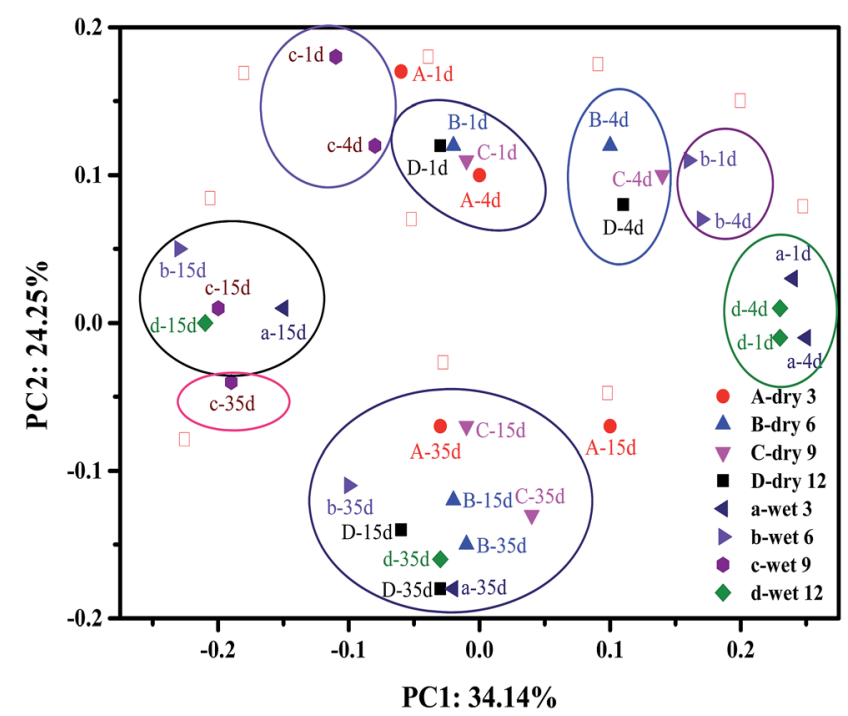

Fig. 3 Principal component analysis (PCA).

Dominant archaea included Methanosaeta, Methanospirillum, Thermogymnomonas, Methanosphaerula, Methanosarcina, and Methanolinea.
As shown in Fig. 4a, the most abundant bacteria at the genus level were Levilinea in samples from dry milled grass $\mathrm{AD}$, followed by Bacteroides, at relative abundances of $2.33-27.76 \%$ and $0.4-24.94 \%$, respectively. The two most abundant genera in the samples of wet milling treatment were Bacteroides and Levilinea (Fig. 4b), with relative abundance of $0.18-42.01 \%$ and $0.14-$ $37.12 \%$, respectively. Levilinea abundance was drastically reduced on day 4 of fermentation in dry $3(11.98 \%)$, more so than in dry $6(9.13 \%)$, dry $9(8.26 \%)$, or dry $12(8.18 \%)$. This may have been caused by acidification of the sample. As shown in Fig. $4 \mathrm{~b}$, the relative abundance of Bacteroides decreased with increasing fermentation time.

Some of the archaea, such as Methanosaeta, Methanospirillum, Thermogymnomonas, Methanosphaerula, Methanosarcina, and Methanolinea, occupied dominant positions in the fermentation process (Fig. $4 \mathrm{c}$ and d). The most abundant archaea at the genus level were Methanospirillum (up to 56.83\% for wet 6 at 35 days), followed by Methanosaeta (up to $50.77 \%$ for dry 3 at 35 days), in dry and wet milled grass AD. For samples from dry and wet milled grass $\mathrm{AD}$, after 15 days of digestion the relative abundance of Methanospirillum increased significantly; however, the relative abundance of Thermogymnomonas decreased significantly after 15 days of fermentation. This may have been due to the close correlation of Methanospirillum to the 

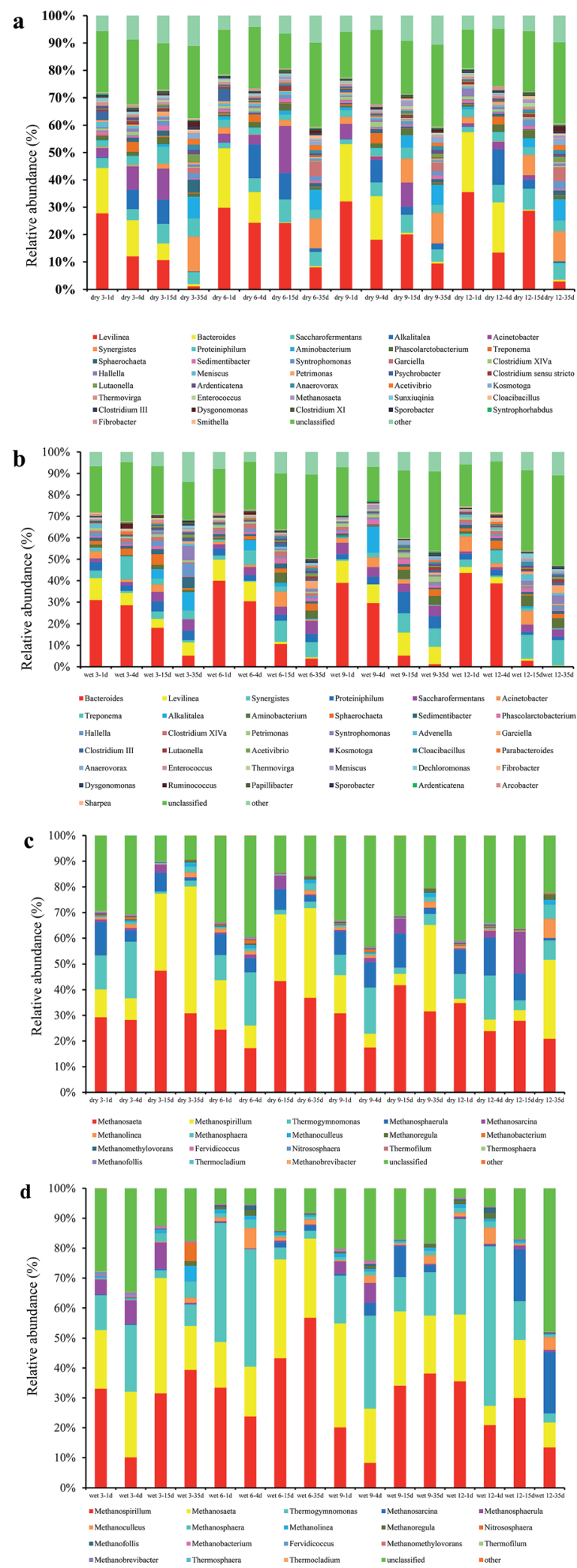

Fig. 4 Relative microbial abundances at the genus level for (a) bacteria in dry milled grass, (b) the most abundant bacteria in wet milled grass, (c) archaea in dry milled grass, and (d) archaea in wet milled grass. methanogenic phase of AD. Thermogymnomonas was closely related to the hydrolysis of cellulose.

\section{Conclusions}

The use of a planetary ball mill can effectively reduce the particle size of the Pennisetum hybrid. Dry milling was more efficient than wet milling for a given processing time. The effects of milling were visually evident, and the pore diameters, pore volumes, and specific surface areas of the grass were altered. The CrI increased with increasing treatment time. The particle-size reduction significantly increased the digestibility of the raw material. Excessive breakage caused acidification, as detected by increasing concentrations of VFAs and changes in microbiological populations. This investigation showed a $41.04 \%$ increase in the specific $\mathrm{CH}_{4}$ yields after $3 \mathrm{~h}$ of dry milling pre-treatment, and indicated that the milling pretreatment of the Pennisetum hybrid was effective in improving the $\mathrm{CH}_{4}$ yield. In addition, wet milling pre-treatment can improve the mobility of raw materials. Good fluidity and optimization of the degree of milling pre-treatment could, therefore, be applied on an industrial scale.

\section{Acknowledgements}

This material is based upon work that is supported by the Science and Technology Service Network Initiative (KFJ-Ew-STS138) and National Science and Technology Support Program: Key technology and engineering demonstration of lignocellulosic biomass energy conversion (2013BAD22B03). The authors wish to thank Mr Lianhua Li (Guangzhou Institute of Energy Conversion, CAS Key Laboratory of Renewable Energy, Chinese Academy of Sciences) for reading the manuscript and providing useful suggestions.

\section{References}

1 A. Mshandete, et al., Effect of particle size on biogas yield from sisal fibre waste, Renewable Energy, 2006, 31(14), 2385-2392.

2 S. Palit, A. K. Chowdhuri and B. K. Mandal, Environmental impact of using biodiesel as fuel in transportation: a review, International Journal of Global Warming, 2011, 3(3), 232-256.

3 C. L. Mao, et al., Review on research achievements of biogas from anaerobic digestion, Renewable Sustainable Energy Rev., 2015, 45, 540-555.

4 Billion-Ton Update: Biomass Supply for a Bioenergy and bioproducts Industry, O. R. N. Laboratory, U. S. D. o. Energy, 2011.

5 J. Z. Zhang, et al., Biomass to bio-ethanol: The evaluation of hybrid Pennisetum used as raw material for bio-ethanol production compared with corn stalk by steam explosion joint use of mild chemicals, Renewable Energy, 2016, 88, 164-170.

6 C. Somerville, et al., Feedstocks for Lignocellulosic Biofuels, Science, 2010, 329(5993), 790-792. 
7 S. Xiulan, C. Ping and Z. Yulei, study on the suitable cutting dates and stubble heights of the new strainNo. 1 of hybrid Pennisetum in late autumn, Chinese Journal of Grassland, 2010, 329(4), 35-41.

8 C. Zhitong, H. Shuilin and H. Yibin, Research progress of Pennisetum rich, Acta Agrestia Sin., 2010, 18(5), 740-748.

9 M. J. Taherzadeh and K. Karimi, Pretreatment of lignocellulosic wastes to improve ethanol and biogas production: A review, Int. J. Mol. Sci., 2008, 9(9), 1621-1651.

10 E. Brun, Improved anaerobic digestion of energy crops and agricultural residues, in Department of Environmental Engineering, in Technical, University of Denmark, 2010.

11 T. Noike, Characteristics of Carbohydrate Degradation and the Rate-Limiting Step in Anaerobic-Digestion, Biotechnol. Bioeng., 1985, 27(10), 1482-1489.

12 I. Angelidaki and B. K. Ahring, Methods for increasing the biogas potential from the recalcitrant organic matter contained in manure, Water Sci. Technol., 2000, 41(3), 189194.

13 A. Barakat, H. de Vries and X. Rouau, Dry fractionation process as an important step in current and future lignocellulose biorefineries: A review, Bioresour. Technol, 2013, 134, 362-373.

14 J. A. Muller, Comminution of organic material, Chem. Eng. Technol., 2003, 26(2), 207-217.

15 Z. H. Hu, H. Q. Yu and R. F. Zhu, Influence of particle size and $\mathrm{pH}$ on anaerobic degradation of cellulose by ruminal microbes, Int. Biodeterior. Biodegrad., 2005, 55(3), 233-238.

16 F. Monlau, et al., Lignocellulosic Materials Into Biohydrogen and Biomethane: Impact of Structural Features and Pretreatment, Crit. Rev. Environ. Sci. Technol., 2013, 43(3), 260-322.

17 F. Monlau, et al., Do furanic and phenolic compounds of lignocellulosic and algae biomass hydrolyzate inhibit anaerobic mixed cultures? A comprehensive review, Biotechnol. Adv., 2014, 32(5), 934-951.

18 A. Pakarinen, et al., Evaluation of preservation methods for improving biogas production and enzymatic conversion yields of annual crops, Biotechnol. Biofuels, 2011, 4(1), 20.

19 R. T. Romano, et al., The effect of enzyme addition on anaerobic digestion of Jose Tall Wheat Grass, Bioresour. Technol., 2009, 100(20), 4564-4571.

$20 \mathrm{~S}$. Kavitha, et al., Enhancing the functional and economical efficiency of a novel combined thermo chemical disperser disintegration of waste activated sludge for biogas production, Bioresour. Technol., 2014, 173, 32-41.

21 S. Kavitha, et al., Combined thermo-chemo-sonic disintegration of waste activated sludge for biogas production, Bioresour. Technol., 2015, 197, 383-392.

22 Standard Methods for the Examination of Water and Wastewater, A. P. H. Association, 1998.
23 A. Rademacher, et al., Characterization of microbial biofilms in a thermophilic biogas system by high-throughput metagenome sequencing, FEMS Microbiol. Ecol., 2012, 79(3), 785-799.

$24 \mathrm{H}$. Tamaki, et al., Analysis of 16S rRNA Amplicon Sequencing Options on the Roche/454 Next-Generation Titanium Sequencing Platform, PLoS One, 2011, 6(9), e25263.

25 J. G. Caporaso, et al., QIIME allows analysis of highthroughput community sequencing data, Nat. Methods, 2010, 7(5), 335-336.

26 R. C. Edgar, et al., UCHIME improves sensitivity and speed of chimera detection, Bioinformatics, 2011, 27(16), 2194-2200.

27 M. Wiman, et al., Rheological Characterization of Dilute Acid Pretreated Softwood, Biotechnol. Bioeng., 2011, 108(5), 1031-1041.

28 H. B. Zhao, et al., Studying cellulose fiber structure by SEM, XRD, NMR and acid hydrolysis, Carbohydr. Polym., 2007, 68(2), 235-241.

29 S. Park, et al., Cellulose crystallinity index: measurement techniques and their impact on interpreting cellulase performance, Biotechnol. Biofuels, 2010, 3(1), 10.

30 A. Mshandete, et al., Enhancement of anaerobic batch digestion of sisal pulp waste by mesophilic aerobic pretreatment, Water Res., 2005, 39(8), 1569-1575.

31 C. Sambusiti, et al., Benefit of sodium hydroxide pretreatment of ensiled sorghum forage on the anaerobic reactor stability and methane production, Bioresour. Technol., 2013, 144, 149-155.

32 G. Forgacs, et al., Methane production from citrus wastes: process development and cost estimation, J. Chem. Technol. Biotechnol., 2012, 87(2), 250-255.

33 U. Schimpf, et al., Improving the efficiency of large-scale biogas processes: pectinolytic enzymes accelerate the lignocellulose degradation, Energy Environ., 2013, 4, 53-60.

$34 \mathrm{~S}$. Kavitha, et al., Impact of thermo-chemo-sonic pretreatment in solubilizing waste activated sludge for biogas production: Energetic analysis and economic assessment, Bioresour. Technol., 2016, 219, 479-486.

35 R. U. Rani, et al., Combined treatment of alkaline and disperser for improving solubilization and anaerobic biodegradability of dairy waste activated sludge, Bioresour. Technol., 2012, 126, 107-116.

36 H. B. Moller, S. G. Sommer and B. K. Ahring, Biological degradation and greenhouse gas emissions during prestorage of liquid animal manure, J. Environ. Qual., 2004, 33(1), 27-36.

37 Y. Y. Wang, et al., Effects of volatile fatty acid concentrations on methane yield and methanogenic bacteria, Biomass Bioenergy, 2009, 33(5), 848-853.

38 A. Veeken and B. Hamelers, Effect of temperature on hydrolysis rates of selected biowaste components, Bioresour. Technol., 1999, 69(3), 249-254. 